\title{
Design and Fabrication of Ginger Harvesting Machine
}

\author{
M. R. Sanjay, G. R. Arpitha, L. Laxmana Naik, B. Yogesha \\ Department of Mechanical Engineering, Malnad College of Engineering, Hassan, India \\ Email: sanjaymrgech@gmail.com
}

Received 29 September 2015; accepted 27 November 2015; published 30 November 2015

Copyright @ 2015 by authors and Scientific Research Publishing Inc.

This work is licensed under the Creative Commons Attribution International License (CC BY). http://creativecommons.org/licenses/by/4.0/

(c) (i)

\begin{abstract}
Ginger is a potential agricultural commodity to be developed in India. When the harvest comes, people still use a very simple method for harvesting ginger by using hoes, pick-axe and other farming equipments. The farmers complain for the need of so many work forces for harvesting while the labor cost is getting increased and the time spent for harvesting process is too long. Although there is an alternative of imported ginger harvesting machines, those machines are not compatible with the farming environment in India, having a high initial and maintenance cost. This machine can be used in any farming condition in India and can be prepared at village level. This machine has three main parts namely, ginger digger, screener and power transmission system. This project is focusing on design and fabrication ginger harvesting machine. The screener will not only separate ginger from soil but also not let the ginger get harmed. The screener also uses for collectible part, to make this machine need some power transmission system from the engine. This machine needs Auto front petrol engine with rotation speed 20 - $25 \mathrm{rpm}$ approximately with the aid of gear reduction.
\end{abstract}

\section{Keywords}

Ginger, Farming Environment, Digger, Screener and Power Transmission System

\section{Introduction}

Ginger (Zingiber officinale) (Family: Zingiberaceae) is an herbaceous perennial, the rhizomes of which are used as a spice. India is a leading producer of ginger in the world and during 2012-13 the country produced 7.45 lakh tonnes of the spice from an area of 157,839 hectares. Ginger is cultivated in most of the states in India [1]. However, states namely Karnataka, Orissa, Assam, Meghalaya, Arunachal Pradesh and Gujarat together contribute 65 percent to the country's total production. Ginger originated in Asia and now grows in several parts of 
the world. The root of the plant is harvested for many culinary and medicinal uses. It can be used in many forms and is edible raw as well as cooked. One of the most common uses of ginger is to relieve nausea and other gastric ailments.

A flowering plant is actually the root of the ginger plant that is harvested. A single root can have many offshoots above ground. The portion of the plant above ground has slender stalks with long leaves that come to a point. The flowers grow in clusters and are green and purple. Ginger is a tropical plant that is found in the Caribbean, India, Southeast Asia, and West Africa. Though the full name is root ginger, it is usually just called ginger.

Traditionally ginger plant is harvested manually to get the ginger out of ground. But it consumes more time and more physical exertion of worker. It is necessary to introduce machine to harvest to reduce time consumption and human efforts. A machine of this nature can be fabricated at village level application in India such as to harvest at minimum time and a minimum cost, to get ginger as quickly as possible from the field, to reduce the physical exertion, to avoid physical damage to Ginger, to reduce man power and to ensure the safety to labors.

\section{Processing of Ginger}

Processing of ginger to produce dry ginger basically involves two stages-peeling of the ginger rhizomes to remove the outer skin and sun drying to a safe moisture level. Peeling-Peeling serves to remove the scaly epidermis and facilitate drying. Peeling of fully matured rhizomes is done by scrapping the outer skin with bamboo splits having pointed ends and this accelerates the drying process. Deep scraping with knifes should be avoided to prevent the damage of oil bearing cells which are present just below the outer skin. Excessive peeling will result in the reduction of essential oil content of the dried produce. The peeled rhizomes are washed before drying.

The dry ginger so obtained is valued for its aroma, flavour and pungency. Indian dried gingers are usually rough peeled when compared to Jamaican gingers, which are clean peeled. The rhizomes are peeled only on the flat sides and much of the skin in between the fingers remains intact. The dry ginger so produced is known as the rough peeled or unbleached ginger and bulk of the ginger produced in Kerala are of this quality.

\section{Methodology}

\subsection{Force Determination}

Before going to design a harvesting machine, it is necessary to know the force required to dig/penetrate the ginger bed and get ginger out of bed shown in Figure 1. The set up was fabricated as per the drawing shown in Figure 3 to determine the force required to penetrate the blade into the bed. The blades are similar to pick-axe in construction, and then fabrication was carried out .The legs i.e. structural support were placed along the bed in such way that the bed has to come exactly at middle of the legs. By conducting this experiment (by trial and error method), it was concluded that the force/load required to penetrate the blade into the bed is $42 \mathrm{~kg}$ (considering the maximum force). Figure 2 shows Bed and Trench Representation and Table 1 represents force reading taken in ginger fields.

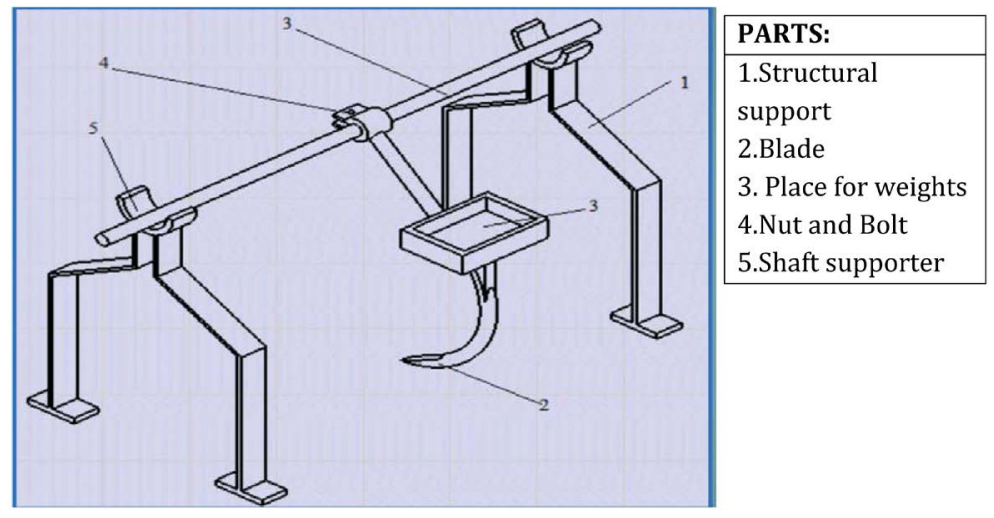

Figure 1. Arrangement of force determination. 


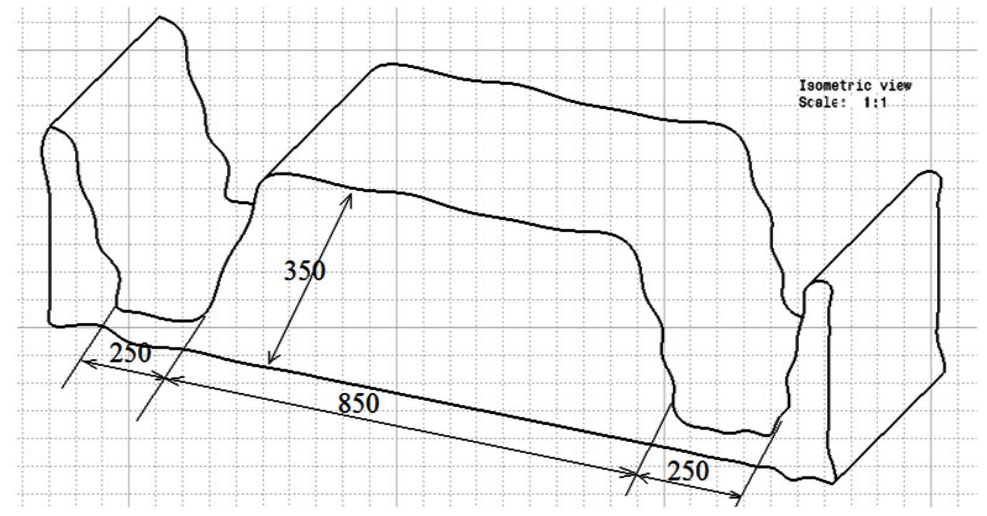

Figure 2. Bed and trench representation.

1. C-Channel (Structural Member)

2. Shaft of Dia. $44 \mathrm{~mm}$

3. Blades

4. Engine

5. Bearing

6. Bolt (M12)

\section{Washer}

8. Nut
10. Wheel

11. Wheel Washer

12. Cotter Pin

13. Base C-Channel

14. Engine Base

15. Larger Chain Sprocket

16. Smaller Chain Sprocket

9. Wheel Shaft of Dia. $25 \mathrm{~mm}$ 18. Blade Cup

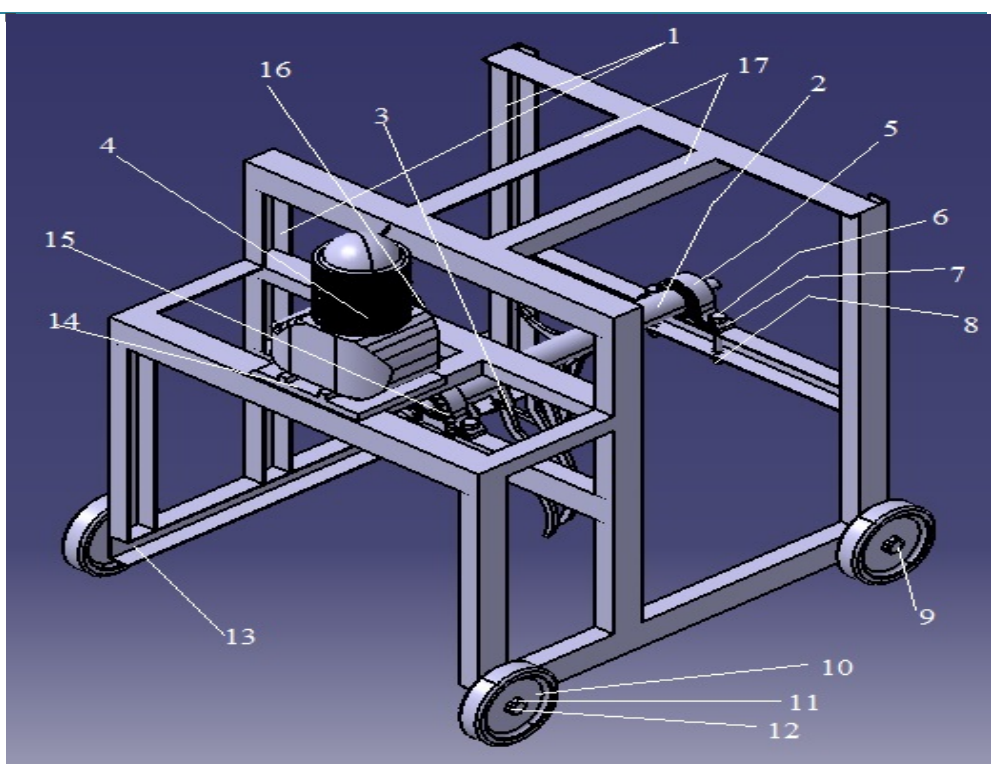

Figure 3. Assembly drawing.

Considering maximum average force, i.e. $=42 \mathrm{~kg}$.

Torque $=$ Force $\times$ Perpendicular distance (Length of blade in meters)

$$
\begin{aligned}
& =42 \times 9.8 \times 0.35 \\
& =144.06 \mathrm{~N} \cdot \mathrm{m}
\end{aligned}
$$


Table 1. Force readings.

\begin{tabular}{ccccc}
\hline & \multicolumn{2}{c}{ Bed No. } & Applied Load (kg) & Average Load (kg) \\
\hline & 01 & 40 & 41 & 40.5 \\
Land No. 1 & 02 & 38 & 39 & 38.5 \\
& 03 & 41 & 42 & 41.5 \\
& 04 & 39 & 41 & 40 \\
Land No. 2 & 42 & 41 & 41.5 \\
& 02 & 40 & 41 & 40.5 \\
\hline
\end{tabular}

\section{Selection of Engine}

Since the 50 - 60 rotation per minute is required for the blades of machine to get ginger out of bed. Hence the power of the engine is given by $(N)$;

$N=(2 \pi n T / 60000) \mathrm{kW}$

Where, $N \rightarrow$ Power of Engine in $\mathrm{kW}$.

$n \rightarrow$ No. of Rotations per Minute in rpm.

$T \rightarrow$ Torque to be transmitted in $\mathrm{N} \cdot \mathrm{mm}$.

$N=(2 \times 3.142 \times 60 \times 144.06 \times 1.5) / 60000(1.5$ for initial torque $)=1.36 \mathrm{~kW}$

\section{Hence Auto front engine is selected which has capacity 150 cc.}

\subsection{CAD Model}

Figure 3 shows assembly drawing of ginger machine done by CATIA V5. It contains various parts such as CChannel, blades, engine, bearing, chain sprocket and blade cup.

\subsection{Design of Chain Drives}

Selected chain shown in Figure 4-L 85 SL [2] (from iwis designation)

Design parameters of chain drives

1) Pitch of the chain (Assuming the Pitch of the chain to be 12.7 which is commercially available in the market).

From DDHB,

Break load $\left(F_{u}\right)=22000 \mathrm{~N} \quad$ (made by iwis company);

Measuring load $(w)=65 \mathrm{~N}$.

2) Number of teeth on sprockets

Assuming the number of teeth of small sprocket (driver sprocket) to be 11 ,

We have;

Velocity ratio $(i)=$ number of teeth on driven sprocket/number of teeth on driver sprocket;

$4=Z_{2} / 11$;

$Z_{2}=44$

Therefore the no. of teeth on larger sprocket is 44 .

3) Pitch diameter of sprockets 


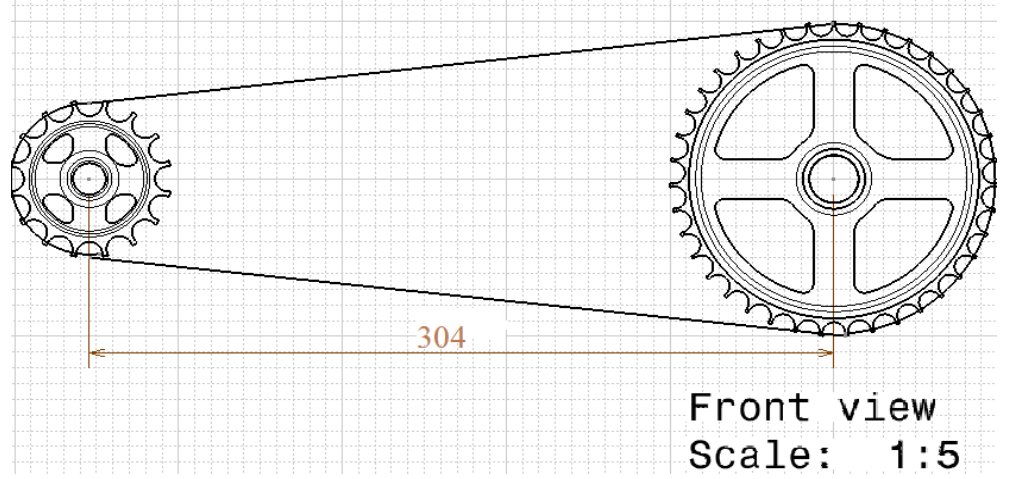

Figure 4. Chain drive.

We have

$d=p / \sin (180 / z) \quad$ (from DDHB)

Pitch diameter of smaller sprocket $\left(d_{1}\right)=p / \sin \left(180 / z_{1}\right)$

$$
\begin{aligned}
& =12.7 / \sin (180 / 11) \\
& =45.07 \mathrm{~mm}
\end{aligned}
$$

Pitch diameter of larger sprocket $\left(d_{2}\right)=p / \sin \left(180 / z_{2}\right)$

$$
\begin{aligned}
& =12.7 / \sin (180 / 44) \\
& =178.02 \mathrm{~mm}
\end{aligned}
$$

\section{4) Velocity of sprocket}

$$
\begin{aligned}
(v) & =\left(p n_{1} Z_{1}\right) /(60 \times 103) \\
& =12.7 / \sin (180 / 44) 12.7 / \sin (180 / 44) \\
& =2.0955 \mathrm{~m} / \mathrm{s}
\end{aligned}
$$

\section{5) Required pull}

$$
\begin{aligned}
(F) & =1000 \mathrm{~N} / v \\
& =1000 \times 4.0 / 2.0955 \\
& =1908.85 \mathrm{~N}
\end{aligned}
$$

6) Allowable pull $\left(F_{a}\right)=F_{u} / n_{o}$

$$
\begin{aligned}
\text { For } p= & 12.7 \text { and speed }=900 \text { FOS is selected to be } 10.6 \quad \text { (From DDHB) } \\
n_{o}= & 10.6 \\
n_{o} \rightarrow \text { factor of safety } & \\
& F_{a}=22000 / 10.6 \\
& F_{a}=2075.47 \mathrm{~N}
\end{aligned}
$$

\section{7) Number of strands}

$$
\begin{aligned}
(i) & =F / F_{a} \\
& =1908.85 / 2075.47 \\
& =0.92 \cong 1
\end{aligned}
$$

Therefore the no. of strands required is 1

\section{8) Check for actual factor of safety}


Factor of safety $\left(n_{a}\right)=\left(F_{u} /\left(F+F_{c}+F_{s}\right)\right)$

Where $F_{c}=\left(w v^{2} / g\right)$

$W($ measuring load $)=65 \mathrm{~N}$

$g($ acceleration due to gravity $)=9.81 \mathrm{~m} / \mathrm{s}$

Therefore $F_{c}=\left(65 \times 2.0955^{2} / 9.81\right)$

$$
=29.09 \mathrm{~N}
$$

$F_{s}=K_{2} w C$

Where $K_{2}=$ coefficient of sag $=1$ for vertical position

(from DDHB)

$$
\begin{aligned}
& C=\text { centre distance }=304 \mathrm{~mm} \\
& F_{s}=1 \times 65 \times 0.304=19.76 \mathrm{~N}
\end{aligned}
$$

Factor of safety $\left(n_{a}\right)=22000 /(1908.4+29.06+19.76)$

$$
=11.24
$$

Since $n_{a} \triangleright n_{o}$ then the design is safe.

9) Length of chain in pitch $\left(L_{p}\right)$

$\left(L_{p}\right)=2 \times C_{p} \times \cos \alpha+\left(z_{1}+z_{2} / 2\right)+\alpha\left(z_{2}-z_{1} / 180\right)$

$\alpha=\sin ^{-1}\left(\left(d_{2}-d_{1}\right) / 2 C\right)$

$=\sin ^{-1}((178.02-45.07) / 2 \times 304)$

$=12.60^{\circ}$

Centre distance $(C)=p \times C_{p}$.

It implies that, $C_{p}=C / p=(304 / 12.7)=23.93 \cong 24$.

Therefore, $L_{p}=2 \times 24 \times \cos 12.60+(44+11 / 2)+12.60(44-11 / 180)=76.65$.

Selecting the nearest even no. of pitches is 76 .

10) Length of chain $(L)=L_{p} \times p=76 \times 12.7=965.2 \mathrm{~mm}$.

11) Correct centre distance $(C)$

$L_{p}=2 c / p \cos (\alpha)+\left(z_{1}+z_{2} / 2\right)+\alpha\left(z_{2}-z_{1} / 180\right) ;$

$76=2 \times c / 12.7 \cos (12.6)+(55 / 2)+12.6 \times(33 / 180)$;

It implies that $c=300.54 \mathrm{~mm}$.

\subsection{Design of Shaft}

Figure 5 shows design of shaft. In order to design a rotary tiller, the special work of the tiller and also the performable work of the tractor should be determined. The specific work of rotary tiller is defined as the work carried on by rotary tiller at each rotation of tillage blades per the volume of broken soil, which could be calculated by the following equation (Bernacki et al., 1972) [3]:

$$
A=A_{O}+A_{B}\left(\mathrm{~kg} \cdot \mathrm{m} / \mathrm{dm}^{3}\right)
$$

where: $A_{O}$ and $A_{B}$ are the static specific work and dynamic specific work of rotary tiller $\left(\mathrm{Kg}-\mathrm{m} / \mathrm{dm}^{3}\right)$, respectively, which can be calculated throw the following equations (Bernacki et al., 1972):

$$
\begin{aligned}
& A_{o}=0.1 C_{O} K_{O}\left(\mathrm{~kg} \cdot \mathrm{m} / \mathrm{dm}^{3}\right) \\
& A_{B}=0.001 a_{u} u^{2}\left(\mathrm{~kg} \cdot \mathrm{m} / \mathrm{dm}^{3}\right) \\
& A_{B}=0.001 a_{u} V^{2}\left(\mathrm{~kg} \cdot \mathrm{m} / \mathrm{dm}^{3}\right)
\end{aligned}
$$




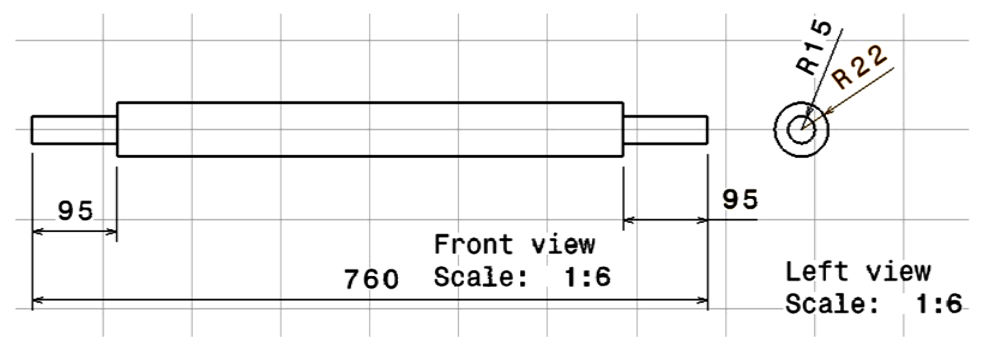

Figure 5. Shaft.

where: $C_{o}$ is the coefficient relative to the soil type, $K_{o}$ is the specific strength of soil $\left(\mathrm{kg} / \mathrm{dm}^{3}\right), u$ is the tangential speed of the blades $(\mathrm{m} / \mathrm{s}), v$ is the forward speed $(\mathrm{m} / \mathrm{s}), a_{u}$ and $a_{v}$ are dynamical coefficients that are relative together throw the following equation:

$$
a_{v}=a_{u} \lambda^{2}\left(\mathrm{~kg} \cdot \mathrm{s}^{2} / \mathrm{m}^{4}\right)
$$

where:

$$
\lambda=u / v
$$

The performable work of the tractor $\left(A_{c}\right)$ could be calculated by the following equation (Bernackiet al, 1972):

$$
A_{c}=\left(7.5 N_{C} \times \eta_{c} \times \eta_{z}\right) / v_{a b}\left(\mathrm{~kg} \cdot \mathrm{m} / \mathrm{dm}^{3}\right)
$$

where: $N_{c}$ is the power of tractor (hp), $v$ is the forward speed $(\mathrm{m} / \mathrm{s})$, $\varsigma$ cis the traction efficiency that its value for the forward rotation of the rotary tiller shaft is 0.9 ; whilst the value for the reverse rotation of the rotary tiller is considered between $0.8-0.9$, çz is the coefficient of reservation of tractor power which is between $0.7-0.8, a$ is the rotary tiller work depth (dm) and $b$ is the tiller work width (dm). Matyashin (1968) reported that at the forward rotation of the rotary tiller shaft, the tillage power consumption is decreased $10 \%-15 \%$, in comparison with the shaft reverse rotation. Hence, in this design the forward rotation was considered for the rotary tiller shaft to reduce the tiller power consumption and also utilization of the rotary tiller thrust force at the forward rotation. In designing the rotary tiller, the hard condition of the soil was considered. The values of Co, Koandauin very heavy soils are 2.5, $50\left(\mathrm{~kg} / \mathrm{dm}^{3}\right)$, and $400\left(\mathrm{~kg} . \mathrm{s}^{2} / \mathrm{m}_{4}\right)$, respectively (Bernacki et al., 1972). Therefore, the static special work of the rotary tiller could be calculated by replacing the values in the Equation (2):

$$
A_{o}=0.1 \times 2.25 \times 50=11.25\left(\mathrm{~kg} \cdot \mathrm{m} / \mathrm{dm}^{3}\right)
$$

Since the values of $b, v, \ddot{e}$ and $a_{v}$ are not given in the Equations (4), (5) and (7), a proper domain should be defined for the values at first, with respect to the technical specifications of the selected power tiller for this design. Then, the optimum condition for the rotary tiller design could be selected from the domain. The recommended work width for the power tiller model of Mitsubishi VST SHAKTI 130DI is $60 \mathrm{~cm}$. The distance between rotary tiller flanges in this design was considered equal to $20 \mathrm{~cm}$. Therefore, the work width domain of the rotary tiller that is the multiple of the distance between the flanges is in the range of 50,60, 70 and $80 \mathrm{~cm}$. This range was selected with respect to the power tiller work width. The forward speed of the power tiller model of Mitsubishi VST SHAKTI 130DI at different transmission gears are presented in Table 2. Because at the high levels of power tiller forward speeds, the penetration ability of the rotary tiller blades in the soil reduces, in this design only the heavy transmission gears were considered as the domain of forward speed. Hendrick and Gill (1971) suggested the minimum value of 2.5 for ë [4].

Hence, a domain from 2 to 22 and from 0.2 to 2 was considered for ë and forward speed, respectively, to provide a large section range for the rotary tiller design. According to the explanations offered above and by Equations (1), (4) and (7), the values of $A$ and $A c$ could be calculated:

$$
\begin{gathered}
A=A_{o}+A_{B}=11.25+0.001 a_{v} v^{2} \\
A_{c}=43.87 / v b
\end{gathered}
$$

By using Equations (8) and (9), the values of $A$ and $A c$ with respect to the defined domain for ë and v are obtained in Table 3 (Mohammadi Alasti et al., 2008). 
Table 2. The forward speed of the power tiller model of mitsubishi VST SHAKTI 130DI at different transmission gears.

\begin{tabular}{ccc}
\hline Transmission Gear & Forward Speed $\mathbf{( k m} / \mathbf{h})$ & Forward Speed $(\mathbf{m} / \mathbf{s})$ \\
\hline 1-Forward-Heavy & 1.80 & 0.50 \\
2-Forward-Heavy & 2.64 & 0.73 \\
3-Forward-Heavy & 4.20 & 1.17 \\
1-Forward-Low & 6.42 & 1.78 \\
2-Forward-Low & 9.50 & 2.64 \\
3-Forward-Low & 15.00 & 4.17 \\
1-Reverse & 1.55 & 0.43 \\
2-Reverse & 5.60 & 1.56 \\
\hline
\end{tabular}

Table 3. The values of specific work of rotary tiller and maximum work of power tiller at different values of $\mathrm{V}$ and $\Lambda$.

\begin{tabular}{|c|c|c|c|c|c|c|c|c|c|c|c|c|c|c|}
\hline & & $\begin{array}{c}\text { Gear } \\
\text { Number }\end{array}$ & & & & 1 High & & 2 High & & 3 High & & & & \\
\hline$\lambda=\mathbf{u} / \mathbf{v}$ & $\mathbf{a}_{\mathrm{v}}$ & $\mathrm{V}(\mathrm{m} / \mathrm{s})$ & 0.2 & 0.3 & 0.4 & 0.5 & 0.6 & 0.73 & 0.8 & 1.17 & 1.2 & 1.4 & 1.6 & 2 \\
\hline 2 & 1600 & & 11.31 & 11.39 & 11.50 & 11.65 & 11.83 & 12.10 & 12.27 & 13.44 & 13.55 & 14.38 & 15.35 & 17.65 \\
\hline 3 & 3600 & & 11.39 & 11.57 & 11.83 & 12.15 & 12.55 & 13.17 & 13.55 & 16.18 & 16.43 & 18.31 & 20.47 & 25.65 \\
\hline 4 & 6400 & & 11.51 & 11.83 & 12.27 & 12.85 & 13.55 & 14.66 & 15.35 & 20.01 & 20.47 & 23.79 & 27.63 & 36.85 \\
\hline 6 & 14400 & & 11.83 & 12.55 & 13.55 & 14.85 & 16.43 & 18.92 & 20.47 & 30.96 & 31.98 & 39.47 & 48.11 & 68.85 \\
\hline 8 & 25600 & & 12.27 & 13.55 & 15.35 & 17.65 & 20.47 & 24.89 & 27.63 & 46.29 & 48.11 & 61.43 & 76.78 & 113.65 \\
\hline 10 & 40000 & & 12.85 & 14.85 & 17.64 & 21.25 & 25.65 & 32.56 & 36.85 & 66.01 & 68.85 & 89.65 & 113.65 & 171.25 \\
\hline 12 & 57600 & $(\mathrm{~kg} \cdot \mathrm{m}$ & 13.55 & 16.43 & 20.47 & 25.65 & 31.98 & 41.94 & 48.11 & 90.09 & 94.19 & 124.15 & 158.71 & 241.65 \\
\hline 14 & 78400 & & 14.38 & 18.30 & 23.79 & 30.85 & 39.47 & 53.02 & 60.43 & 118.57 & 124.15 & 164.91 & 211.95 & 324.85 \\
\hline 16 & 102400 & & 15.35 & 20.46 & 27.63 & 36.85 & 48.11 & 65.82 & 76.78 & 151.42 & 158.71 & 211.95 & 273.39 & 420.85 \\
\hline 18 & 129600 & & 16.43 & 22.91 & 31.98 & 43.65 & 57.91 & 80.31 & 94.19 & 188.65 & 197.87 & 265.27 & 343.03 & 529.65 \\
\hline 20 & 160000 & & 17.65 & 25.65 & 36.85 & 51.25 & 68.85 & 96.51 & 113.65 & 230.27 & 241.65 & 324.85 & 420.85 & 621.25 \\
\hline 22 & 193600 & & 18.99 & 28.67 & 42.23 & 59.65 & 80.95 & 114.42 & 135.15 & 276.27 & 290.03 & 390.71 & 506.87 & 785.65 \\
\hline \multirow{4}{*}{$\begin{array}{c}b \\
(d m)\end{array}$} & 5 & \multirow{4}{*}{$\begin{array}{c}A_{c} \\
\left(\mathbf{k g} \cdot \mathrm{m} / \mathbf{d m}^{3}\right)\end{array}$} & 43.87 & 29.24 & 21.93 & 17.55 & 14.62 & 12.02 & 10.97 & 7.49 & 7.31 & 6.27 & 5.48 & 4.38 \\
\hline & 6 & & 36.56 & 24.37 & 18.28 & 14.62 & 12.18 & 10.01 & 9.17 & 6.25 & 6.09 & 5.22 & 4.57 & 3.65 \\
\hline & 7 & & 31.33 & 20.89 & 15.67 & 12.53 & 10.44 & 8.58 & 7.83 & 5.36 & 5.22 & 4.47 & 3.92 & 3.13 \\
\hline & 8 & & 27.42 & 18.28 & 13.71 & 10.96 & 9.14 & 7.51 & 6.85 & 4.68 & 4.57 & 3.92 & 3.43 & 2.74 \\
\hline
\end{tabular}

The proper selection of the forward speed is dependent to the tangential speed of the blades (that is a function of rotational speed of rotor) and the length of sliced soil. The tangential speed of the blades $(u)$, the rotational speed of the rotor $(n)$, and the length of sliced soil $(L)$ could be obtained by the following equations:

$$
\begin{gathered}
u=(2 \pi n R) / 60000 \\
n=(6000 \lambda v) / 2 \pi R \\
L=(2 \pi R) / \lambda Z
\end{gathered}
$$

In the equations, $R$ is the rotor radius (cm), $v$ is the forward speed $(\mathrm{m} / \mathrm{s})$ and $Z$ is the number of blades on each 
side of the rotor flanges. In this design, two blades were considered on each side of the flanges $(Z=2)$. The working depth selected for the rotary tiller in this design was $15 \mathrm{~cm}$. The conventional diameter for rotary tillers rotor is variable from 30 to $50 \mathrm{~cm}$. Moreover, the radius of rotor for rotary tillers should be selected greater than the working depth (Matyashin, 1968).Considering these explanations, a $50 \mathrm{~cm}$ diameter was diagnosed to be appropriate for the rotary tiller rotor. By replacing the selected value for the rotor diameter in the Equations (11) and (12), we will have:

$$
\begin{gathered}
n=(6000 \lambda v) / 2 \pi \times 25=38.21 \lambda v \\
L=(2 \pi \times 25) / \lambda \times 2=(25 \pi) / \lambda
\end{gathered}
$$

The total possible selections for the rotary tiller working width (b), forward speed (v) and rotational speed of rotor (n) are presented in Table 3. Table 3 is obtained through Equations (13) and (14). Firstly, for each of the selected working widths in Table 3, the closest value of the rotary tiller special work to the performable work of the power tiller was determined at each of the forward speeds. Then, the corresponding values of ë for each forward speed were determined to calculate the rotor speed and the length of sliced soil (Table 3). By selecting the rotary tiller special work and the performable work of the power tiller close together at each of the forward speeds, an appropriate conformity will be continued between the rotary tiller and power tiller.

Kepner (1972) reported that the power needed of the tractor PTO for supplying a rotary tiller should be approximately $1 \mathrm{hp}$ for each centimeter of working width. Considering the suitable domain obtained for the rotor speed, the length of sliced soil and the forward speed, at the working width of $70 \mathrm{~cm}$, this width was selected as a proper working width for the power tiller. Moreover, at the selected working width there was a little difference between the rotary tiller special work and the performable work of the power tiller (Table 4).

Considering the results presented in Table 4, it becomes evident that the selected power tiller for this design only at the gear one can supply a rotary tiller with the working width of $70 \mathrm{~cm}$ and working depth of $15 \mathrm{~cm}$.

After specifying the appropriate working width for the power tiller, the length of sliced soil, the rotational

\begin{tabular}{|c|c|c|c|c|c|c|}
\hline Selection No. & $\begin{array}{l}\text { Working } \\
\text { Width }(\mathrm{cm})\end{array}$ & $\begin{array}{c}\text { Forward } \\
\text { Speed }(\mathrm{m} / \mathrm{s})\end{array}$ & $(\lambda)$ & $\begin{array}{c}\text { Rotor } \\
\text { Speed (rpm) }\end{array}$ & $\begin{array}{c}\text { Length of } \\
\text { Sliced Soil }(\mathrm{cm})\end{array}$ & $\begin{array}{l}\text { Difference between Rotary Tiller Specific Work } \\
\text { and Tractor Maximum Work }\left(\mathrm{kg} \cdot \mathrm{m} / \mathrm{dm}^{3}\right)\end{array}$ \\
\hline 1 & \multirow{5}{*}{50} & 0.2 & 22 & 168.08 & 3.57 & 24.88 \\
\hline 2 & & 0.3 & 22 & 252.12 & 3.57 & 0.57 \\
\hline 3 & & 0.4 & 12 & 183.36 & 6.54 & 1.46 \\
\hline 4 & & 0.5 & 06 & 114.60 & 13.09 & 2.70 \\
\hline 5 & & 0.6 & 04 & 91.68 & 19.63 & 1.07 \\
\hline 6 & \multirow{5}{*}{60} & 0.2 & 22 & 168.08 & 3.57 & 17.57 \\
\hline 7 & & 0.3 & 18 & 206.28 & 4.36 & 1.46 \\
\hline 8 & & 0.4 & 10 & 152.80 & 7.85 & 0.63 \\
\hline 9 & & 0.5 & 04 & 76.40 & 19.63 & 1.77 \\
\hline 10 & & 0.6 & 02 & 45.84 & 39.27 & 0.35 \\
\hline 11 & \multirow{4}{*}{70} & 0.2 & 22 & 168.08 & 3.57 & 12.34 \\
\hline 12 & & 0.3 & 16 & 183.36 & 4.91 & 0.43 \\
\hline 13 & & 0.4 & 08 & 122.24 & 9.82 & 0.32 \\
\hline 14 & & 0.5 & 03 & 57.30 & 26.18 & 0.38 \\
\hline 15 & \multirow{3}{*}{80} & 0.2 & 22 & 168.80 & 3.57 & 8.43 \\
\hline 16 & & 0.3 & 12 & 137.52 & 6.45 & 1.8 \\
\hline 17 & & 0.4 & 06 & 91.68 & 13.09 & 0.16 \\
\hline
\end{tabular}

Table 4. Total possible selections for the rotary tiller working width, forward speed and rotational speed of rotor. 
speed of the rotor and the tangential speed of the blades should be calculated at the selected gear (the forward speed of $0.50 \mathrm{~m} / \mathrm{s}$ ). Before performing the mentioned calculations, the appropriate value of ë proportional to the selected forward speed for the power tiller should be obtained. For this purpose, the special work of the rotary tiller and the performable work of the power tiller should be equal together [5]. Therefore,

By representing the obtained value for ë at the Equations (10), (11) and (12) we will have:

$$
\begin{aligned}
& L=21.92 \mathrm{~cm} ; \\
& n=68.37 \mathrm{rpm} ; \\
& u=1.81 \mathrm{~m} / \mathrm{s} .
\end{aligned}
$$

\section{Design of Rotor Shaft}

For designing the rotor shaft shown in Figure 5, the maximum tangential force which can be endured by the rotor should be considered. The maximum tangential force occurs at the minimum of blades tangential speed is calculated by the following (Bernacki et al., 1972):

$$
K_{s}=C_{s} \times\left(75 N_{c} \eta_{c} \eta_{v}\right) / u_{\min }
$$

$C_{s}$ is the reliability factor that is equal to 1.5 for non-rocky soils and 2 for rocky soils (Berbacki et al., 1972). From Equations (6) and (12), it becomes evident that $u_{\min }$ is obtained at $\lambda_{\min }$; and $\lambda_{\min }$ is obtained at $L_{\max }$. So, we will have:

$$
\begin{gathered}
\lambda_{\min }=(2 \pi R) / Z L_{\max }=(2 \pi \times 25) / 2 \times 21.92=3.58 \\
u_{\text {min }}=v \lambda_{\text {min }}=0.5 \times 3.58=1.79 \mathrm{~m} / \mathrm{s}
\end{gathered}
$$

By representing the values of $\lambda_{\min }$ and $u_{\min }$ at the Equation (16), the maximum tangential force on the rotary tiller shaft will be obtained:

$$
K_{s}=1.5 \times(30 \times 13 \times 0.9 \times 0.75) / 1.79=551.50 \mathrm{~kg}
$$

The maximum moment on the rotor shaft $\left(M_{s}\right)$ is calculated through the following:

$$
M_{s}=K_{s} R=551.50 \times 25=13787.62 \mathrm{~kg} \cdot \mathrm{cm}
$$

In the above equation, $R$ is the rotor radius (cm).

Considering the results obtained above, the rotor should be made from roll steel (AISI 302) having yield stress of $520 \mathrm{MPa}$. The allowable stress on the rotor $\left(\tau_{\text {all }}\right)$ is calculated by the following equation (Mott, 1985):

$$
\tau_{\text {all }}=(0.577 k \sigma y) / f=(300 k) / f
$$

where $\sigma_{y}=500 \mathrm{MPa}$.

In the equation, $k$ is the coefficient of stress concentration equal to 0.75 and $f$ is the coefficient of safety, which is equal to 2. By replacing the values of $k$ and $f$ in the Equation (17):

$$
\tau_{\text {all }}=(300 \times 0.75) / 2=112.5 \mathrm{MPa}=1147.18 \mathrm{~kg} / \mathrm{cm}^{2}
$$

The torsional moment is the most important factor that significantly affects the rotor shaft design (Yatsuk et al., 1981). Considering the equation for calculating the torsional moment on rotating shafts, the proper diameter for the rotary tiller shaft could be obtained [5].

$$
d=\left(16 M_{s} / \tau \pi\right)^{1 / 2}=(16 \times 13787 / 1147.18 \pi)^{1 / 2}=3.94 \mathrm{~cm}
$$

\subsection{Design of Bearing}

Design and Calculation (shown in Figure 6)

Diameter of bearing (bore size) $d=30 \mathrm{~mm}$

Stationary load $\left(F_{r}\right)=($ weight of shaft + weight of blade $)=(16+1.25 \times 8)=26 \mathrm{~kg}=26 \times 9.81=255.06 \mathrm{~N}$

Considering the higher end $\approx 300 \mathrm{~N}$

Working hours $=5$ hours, 5 days/week for 2 years

On the basis of given information,

Select 30 BC 02 SKF from DDHB; 


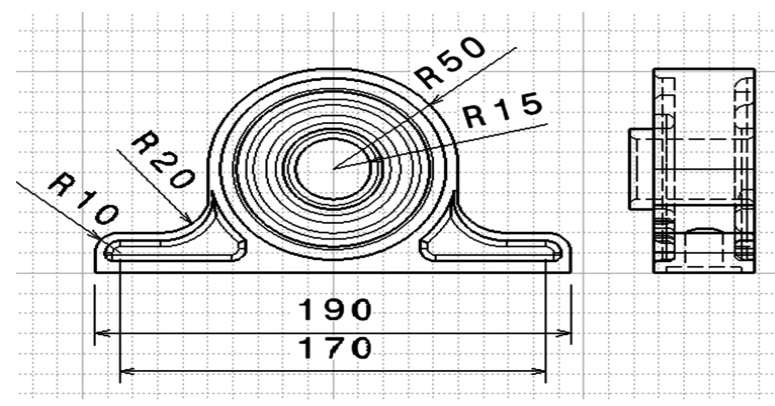

Figure 6. Bearing.

Basic capacity dynamic load $\left(C_{r}\right)=14710 \mathrm{~N}$

Required rated dynamic load $\left(C_{r}\right)=F_{e} \times\left[\left(L_{d} / L_{r}\right) \times\left(n_{d} / n_{r}\right)\right]^{1 / m}$

$F_{e} \rightarrow$ Equivalent load $=V \times F_{r} \times K_{a} \times K_{t}$

where $V \rightarrow$ Rotation factor $=1$ (if inner race is rotating)

$=1.2$ (if outer race is rotating)

$K_{a} \rightarrow$ load application factor $=1.5$ for light shock

$K_{t} \rightarrow$ temperature factor $=1$ (assuming bearing working at normal temperature)

Substituting, $F_{e}=1 \times 300 \times 1.5 \times 1=450 \mathrm{~N}$

$L_{d} \rightarrow$ design life $=5 \times 5 \times 52 \times 2=2600 \mathrm{hr}$

$L_{r} \rightarrow$ rated life $=500 \mathrm{hr}$

$n_{d} \rightarrow$ design speed $=100 \mathrm{rpm}$

$n_{r} \rightarrow$ rated speed $=100 / 3 \mathrm{rpm}$

Substituting, $C_{r}=300 \times[(2600 / 500) \times(100 /(100 / 3))]^{1 / 3}=749.599 \mathrm{~N}$

Bearing No. 6206 is suitable since whose rated dynamic capacity is greater than the required. Hence selected bearing is $30 \mathrm{BC} 02$ SKF and its specifications are [6],

Bearing No. $=6206$

Bore size $(d)=\mathbf{3 0} \mathbf{~ m m}$

Outer diameter $(D)=\mathbf{6 2} \mathbf{~ m m}$

Width $(B)=16 \mathbf{~ m m}$

Fillet radius $=\mathbf{1 . 5} \mathbf{~ m m}$

\subsection{Design of Blade}

Design of blade (shown in Figure 7)

Force $(F)=42 \mathrm{~kg}=412.02 \mathrm{~N}$

Assuming $150 \%$ more force for the initial dig

i.e. $F=618.03 \mathrm{~N} \cong 618 \mathrm{~N}$

Considering a section of $\mathbf{a}-\mathbf{b}$,

Inner radius $\left(r_{i}\right)=90 \mathrm{~mm}$

Outer radius $\left(r_{o}\right)=120 \mathrm{~mm}$

Distance of centroidal axis from the inner fibre

$$
\begin{aligned}
\left(C_{1}\right) & =(h / 3) \times c\left(b_{i}+2 b_{0} / b_{i}+b_{0}\right) \\
& =30 / 3 \times(6+2 \times 3 / 6+3)=13.33 \mathrm{~mm}
\end{aligned}
$$

Radius of centroidal axis $\left(r_{c}\right)=r_{i}+C_{1}=90+13.33=103.33 \mathrm{~mm}$

Radius of neutral axis

$$
\begin{aligned}
\left(r_{n}\right) & =\left(1 / 2 h\left(b_{i}+b_{o}\right)\right) /\left(\left(b_{i} \times r_{o}-b_{0} \times r_{i}\right) / h\right) \ln \left(r_{o} / r_{i}\right) \times-\left(b_{i}-b_{0}\right) \\
& =1 / 2 \times 30(6+3) /((6 \times 120-3 \times 90) / 30) \ln (120 / 90)-(3)=102.64 \mathrm{~mm}
\end{aligned}
$$




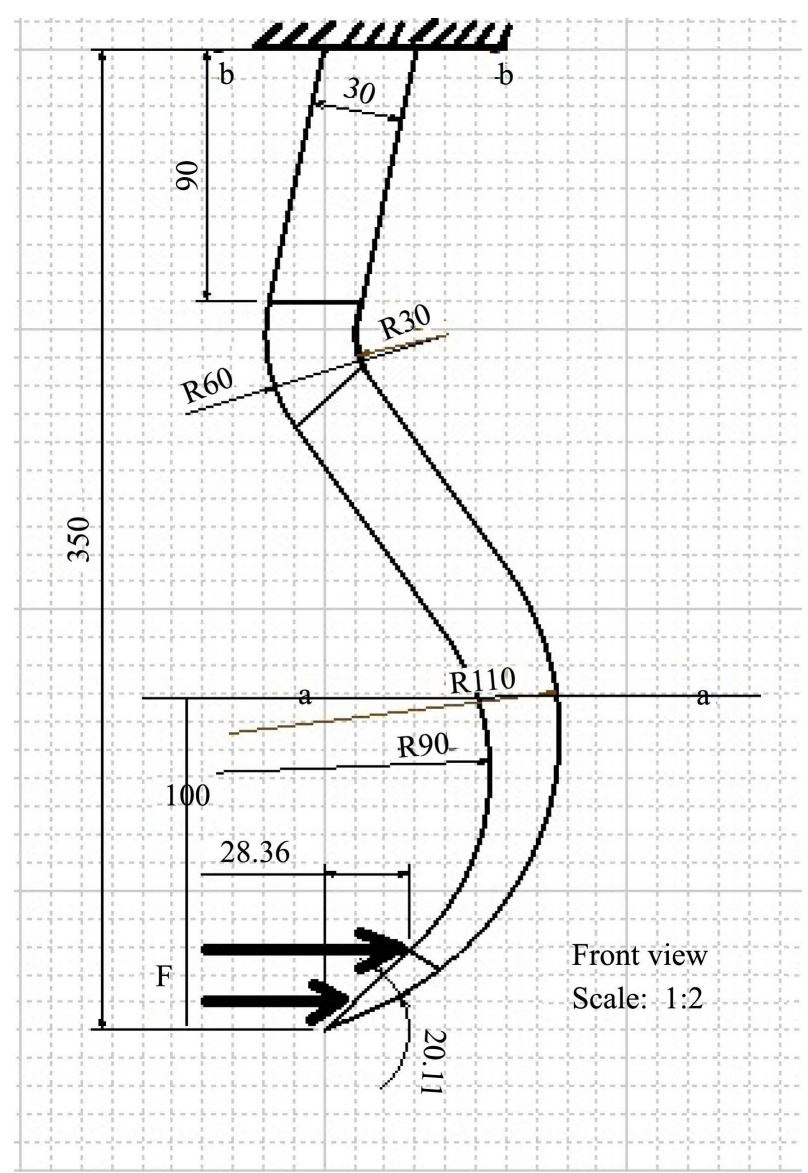

Figure 7. Blade (from DDHB).

Distance of neutral axis from centroidal axis $(e)=r_{c}-r_{n}=103.33-102.64=0.69 \mathrm{~mm}$

Area of cross section at a-a $(A)=1 / 2\left(b_{i}+b_{o}\right) \times h=1 / 2(6+3) \times 30=135 \mathrm{~mm}^{2}$

Distance of neutral axis to inner radius $\left(C_{i}\right)=r_{n}-r_{i}=102.64-90=12.64 \mathrm{~mm}$

Distance of neutral axis to outer radius $\left(C_{o}\right)=r_{o}-r_{n}=120-102.64=17.36 \mathrm{~mm}$

Applied force $(F)=618 \mathrm{~N}$

Bending moment $\left(M_{b}\right)=F \times L=618 \times 100=61800 \mathrm{~N} \cdot \mathrm{mm}$

Direct stress $\left(\sigma_{d}\right)=F / A=618 / 135=4.578 \mathrm{~N} / \mathrm{mm}^{2}$

Bending stress at inner fibre

$$
\begin{aligned}
\left(\sigma_{b i}\right) & =\left(M_{b} \times C_{i}\right) /\left(A \times e \times r_{i}\right) \\
& =(61800 \times 12.64) /(135 \times 0.69 \times 90) \\
& =93.17 \mathrm{~N} / \mathrm{mm}^{2} \quad(\text { tensile })
\end{aligned}
$$

Bending stress at outer fibre

$$
\begin{aligned}
\left(\sigma_{b o}\right) & =\left(M_{b} \times C_{o}\right) /\left(A \times e \times r_{o}\right) \\
& =(61800 \times 17.36) /(135 \times 0.69 \times 120) \\
& =-95.97 \mathrm{~N} / \mathrm{mm}^{2} \quad(\text { compressive })
\end{aligned}
$$

Combined stress at inner fibre $\left(\sigma_{r i}\right)=\sigma_{d}+\sigma_{b i}=4.578+93.17=97.748 \mathrm{~N} / \mathrm{mm}^{2}$

Combined stress at inner fibre

$\left(\sigma_{\text {comb }}\right)=\sigma_{d}+\sigma_{b o}=4.578-95.97=-91.392 \mathrm{~N} / \mathrm{mm}^{2}$

Maximum shear stress 
$\left(\tau_{\max }\right)=0.5 \times \sigma_{\text {max }}=0.5 \times 97.748=48.874 \mathrm{~N} / \mathrm{mm}^{2}$

At section b-b,

$C_{1}=13.33 \mathrm{~mm} \& C_{2}=17.667 \mathrm{~mm}$

Area $=300 \mathrm{~mm}^{2}$

Moment of inertia

$$
\begin{aligned}
(I) & =\left(6 b_{2}+6 b_{b o}+b_{o}\right)^{2} \times h^{3} / 36\left(2 b+b_{o}\right) \\
& =(6 \times 102+6 \times 102+102)^{2} \times 30^{3} / 36(2 \times 10+10) \\
& =32500 \mathrm{~mm}^{4}
\end{aligned}
$$

Direct stress $\left(\sigma_{d}\right)=618 / 300=2.06 \mathrm{~N} / \mathrm{mm}^{2} \quad$ (tensile)

Bending stress at inner fibre $\left(\sigma_{b i}\right)=M_{b} \times C_{i} / I=88.76 \mathrm{~N} / \mathrm{mm}^{2}$ (tensile)

Bending stress at outer fibre $\left(\sigma_{b o}\right)=M_{b} \times C_{o} / I=-117.60 \mathrm{~N} / \mathrm{mm}^{2}$ (compressive)

Combined stress $\left(\sigma_{\text {comb }}\right)=-117.06+2.06=-115.54 \mathrm{~N} / \mathrm{mm}^{2}$ (compressive)

Maximum shear stress at section

$$
\left(\tau_{\max }\right)=0.5 \times \sigma_{\max }=0.5 \times(-117.60)=-58.8 \mathrm{~N} / \mathrm{mm}^{2} \quad(\text { compressive })
$$

\subsection{Design of Fastener}

M12 bolts are used to fasten the bearings to chassis (shown in Figure 8).

When the joint is not fluid tight then, $F_{i}=1402.34 d=1402.34 \times 12=16828.08 \mathrm{~N}$

Core diameter $d_{1}=11.188107 \mathrm{~mm}$

Therefore core area $A_{c}=\pi / 4\left(d_{1}\right)^{2}=\pi / 4 \times(11.188107)^{2}=98.31 \mathrm{~mm}^{2}$

For pre-stressed bolt, initial force $\left(F_{i}\right)=$ allowable stress $\times$ core area of bolt

$16828.08=\sigma \times 98.31$

Therefore, allowable stress $(\sigma)=171.17 \mathrm{~N} / \mathrm{mm}^{2}$

\subsection{Design of Chassis}

Chassis (shown in Figure 9) consists of L-Angular (shown in Figure 10) and C-channels as structural members.

\subsubsection{L-Angles}

Steel Angle is used in industrial maintenance, agricultural implements, transportation equipment, etc.

Material of L-Angles used: Mild Steel

- Also called as: HR steel angle, Mild steel angle, steel L;

- Applications: Frame work, braces, supports, cross members, etc.;

- Workability: Easy to Weld, Cut, Form, and Machine.

Steel Angle or L-Angle is a hot rolled, mild steel angle shape with inside radius corners that is ideal for all

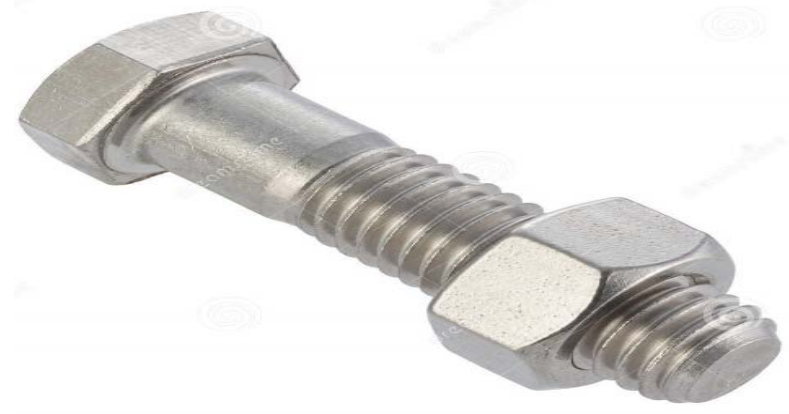

Figure 8. Bolt and Nut (from DDHB). 


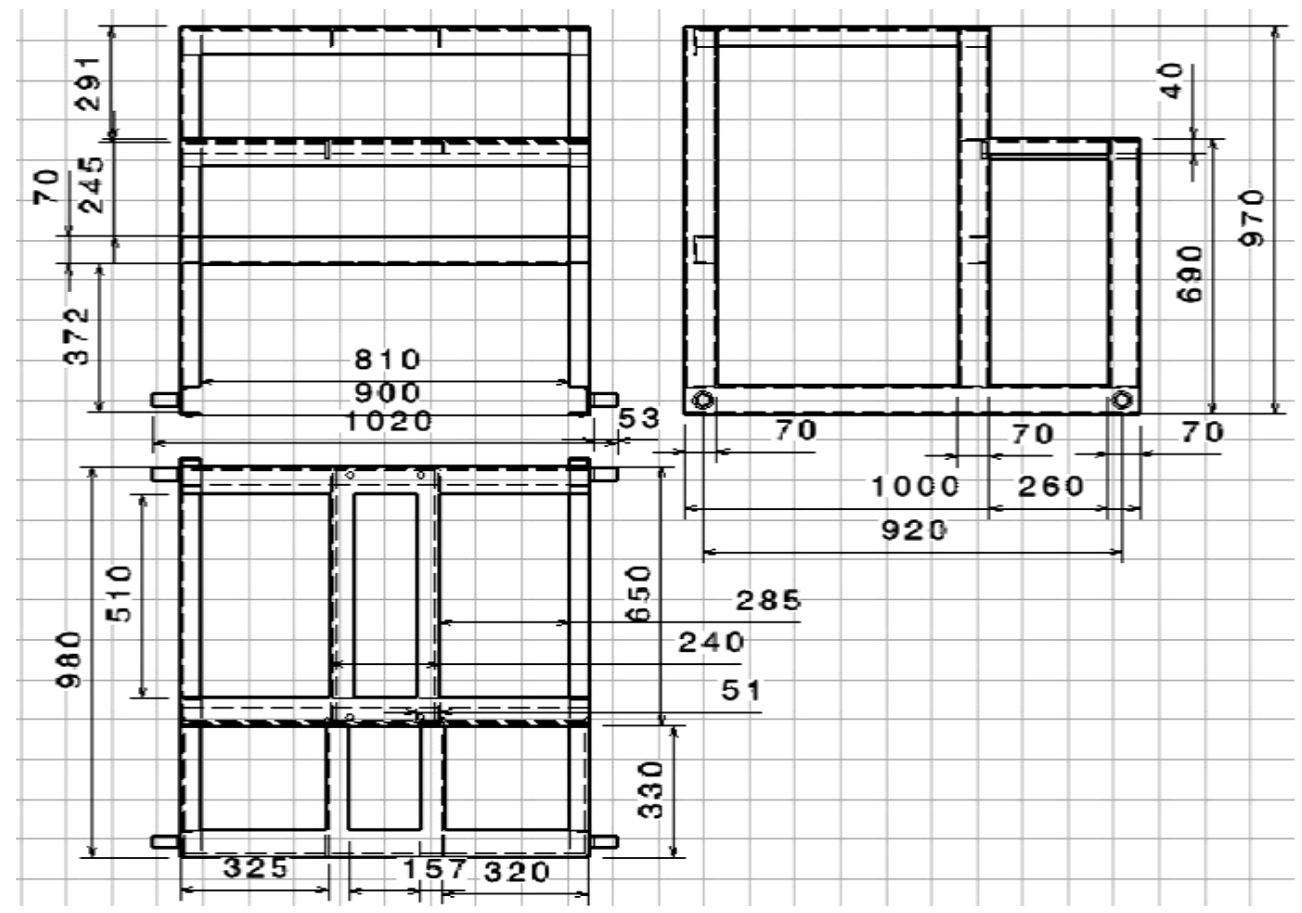

Figure 9. Chassis.

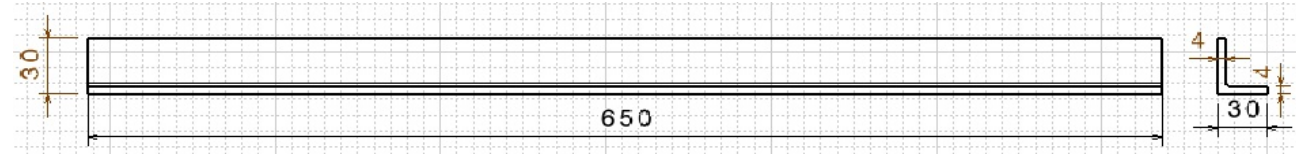

Figure 10. L-Angle.

Table 5. Specification of L-Angle.

\begin{tabular}{cccccc}
\hline Designation & Size $\mathbf{( h * h ) ~} \mathbf{m m}$ & Sectional Area $\left(\mathbf{c m}^{\mathbf{2}}\right)$ & Weight per Meter $\mathbf{( k g )}$ & Thickness $\mathbf{( m m )}$ & Modulus of Section $\left(\mathbf{c m}^{\mathbf{3}}\right)$ \\
\hline ISA 3030 & $30 * 30$ & 2.26 & 1.8 & 4 & 0.8 \\
\hline
\end{tabular}

structural applications, general fabrication and repairs. Table 5 shows specifications of L-Angle which is used in machine.

\subsubsection{C-Channel}

C-Channel as shown Figure 11 used in industrial constructions, agricultural implements, transportation equipment, bridge constructions, etc.

Some of the characteristics are as follows:

- Applications: Frame work, braces, supports, cross members, etc.;

- It is widely used in supporting horizontal load;

- Workability: Easy to Weld, Cut, Form, and Machine.

\subsection{Orthographic Views of the Machine}

Figure 12 represents orthographic views of the ginger machine.

\subsection{Isometric View of Machine}

Figure 13 represents isometric view of the ginger machine.

\section{1) Parts Pictures}




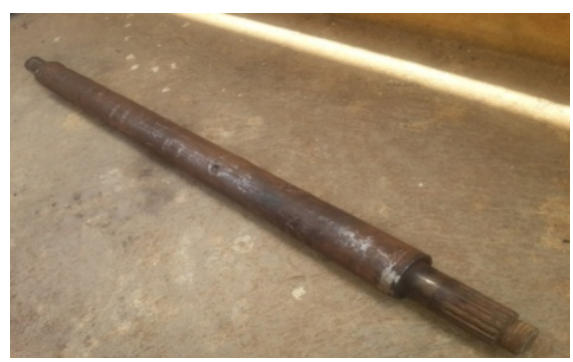

Rotary Shaft

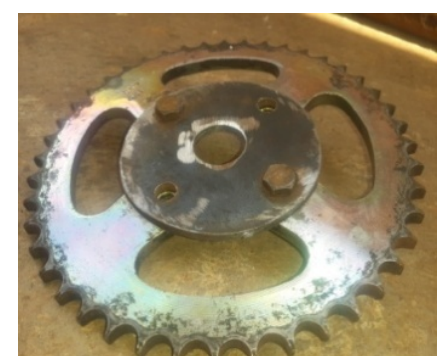

Small Chain Sprocket

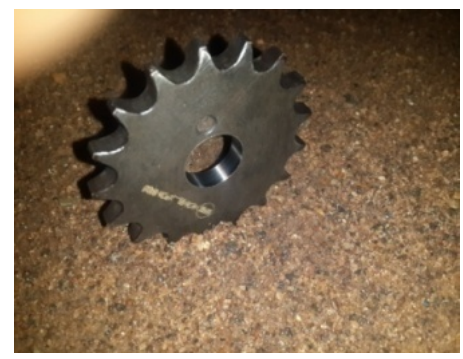

Long Chain Sprocket

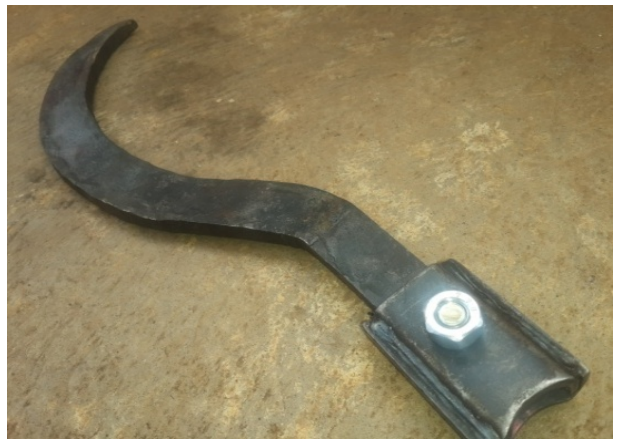

Blade with cup holder

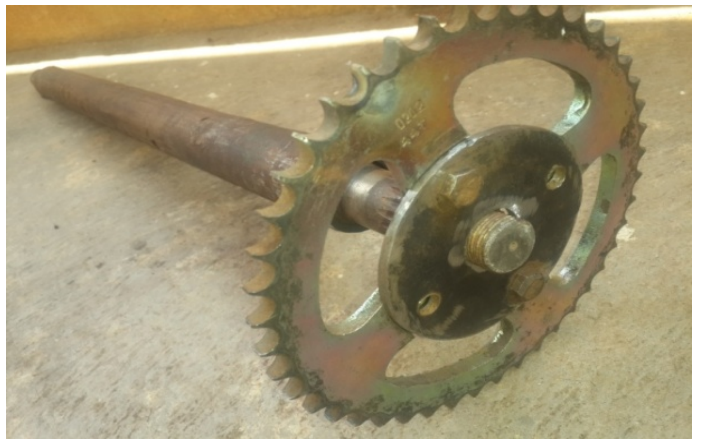

Rotary Shaft with chain sprocket

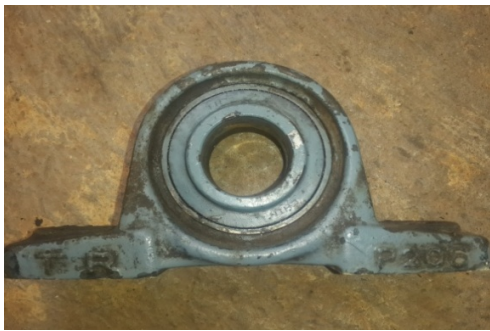

Bearing with Casing

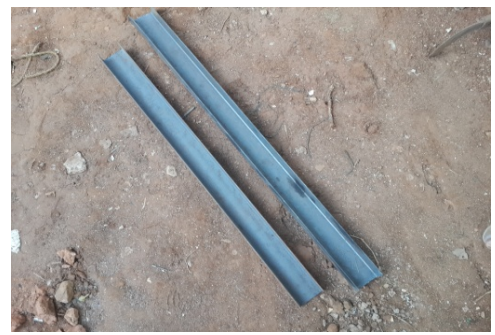

C-Channels

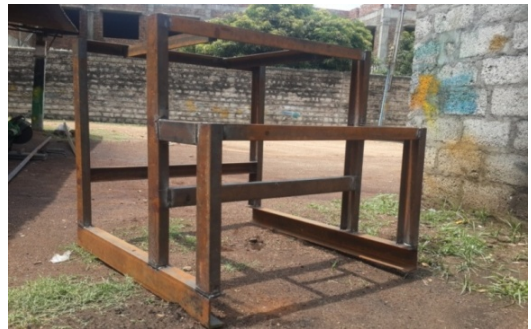

Chassis

\section{2) Fabrication of Different Parts of Machines}

Figure 12 and Figure 13 show orthographic views and isometric view respectively done by CATIA V5. Chassis frame is the main base of the machine on which all components are mounted with wheels and engine. As per the design, marking has done on each C-channels and L-angular. As per the marking, they are cut by cutting machine and holes are drilled by using drilling machine for fixing the plumber blocks to hold shaft along with blades assembly on the chassis are used.

The base C-channels are to $1000 \mathrm{~mm}$ length with the aid of cutting machine, four shafts of $25 \mathrm{~mm}$ diameter and length of $55 \mathrm{~mm}$ are welded using welding machine at distance of $920 \mathrm{~mm}$. Six vertical C-channels of 800 $\mathrm{mm}$ and $560 \mathrm{~mm}$ are cut and welded on base C-channel. Two C-channels of $900 \mathrm{~mm}$ length and welded horizontally to the frame to provide platform for the Plummer blocks. The engine platform is also carried out in the same manner as shown in Figure 14 and Figure 15.

The blades are forged to the required shape and size, and fastened to blade cup holder with the aid of M10 $\times 1.25$ bolts and nut. This assembly is then welded to shaft, in flute angled manner (the angle between each blade is approximately $20^{\circ}$ to $25^{\circ}$ ) at a distance of $75 \mathrm{~mm}$. Then the shaft is fixed in Plummer blocks on either side of shaft. The engine is mounted on platform which is made on the chassis for transmitting power to rotary shaft.

The ginger harvesting machine consists of three main parts, they are:

1) Power Transmission System: This section provides power to the machine it mainly includes Auto front engine and gear box.

2) Digger: Blades are also called as digger which gets the ginger out from bed.

3) Screener: Screener is nothing but the mesh welded on the blade continuously as shown in Figure 15. 


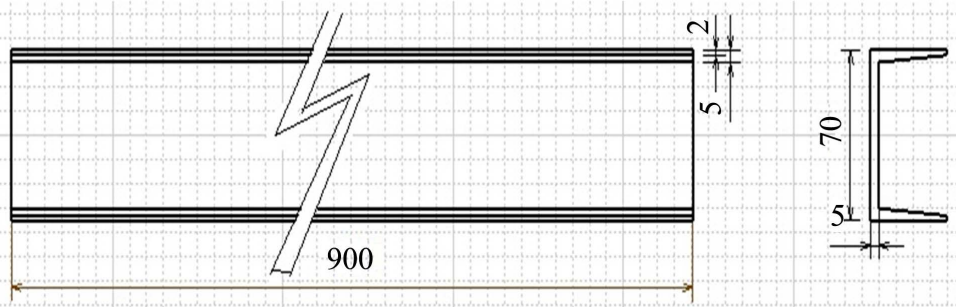

\section{Figure 11. C-Channel.}

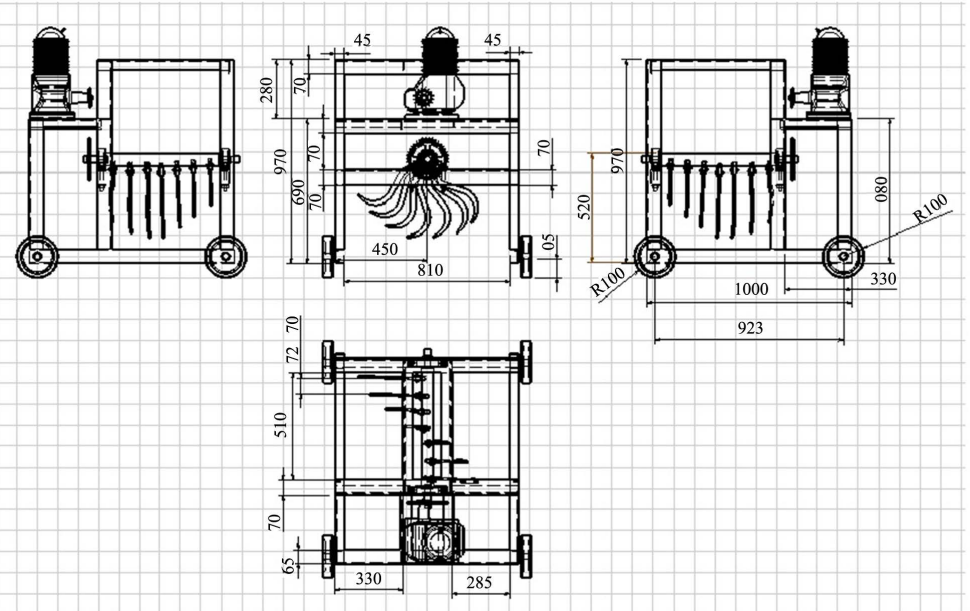

Figure 12. Orthographic views of machine.

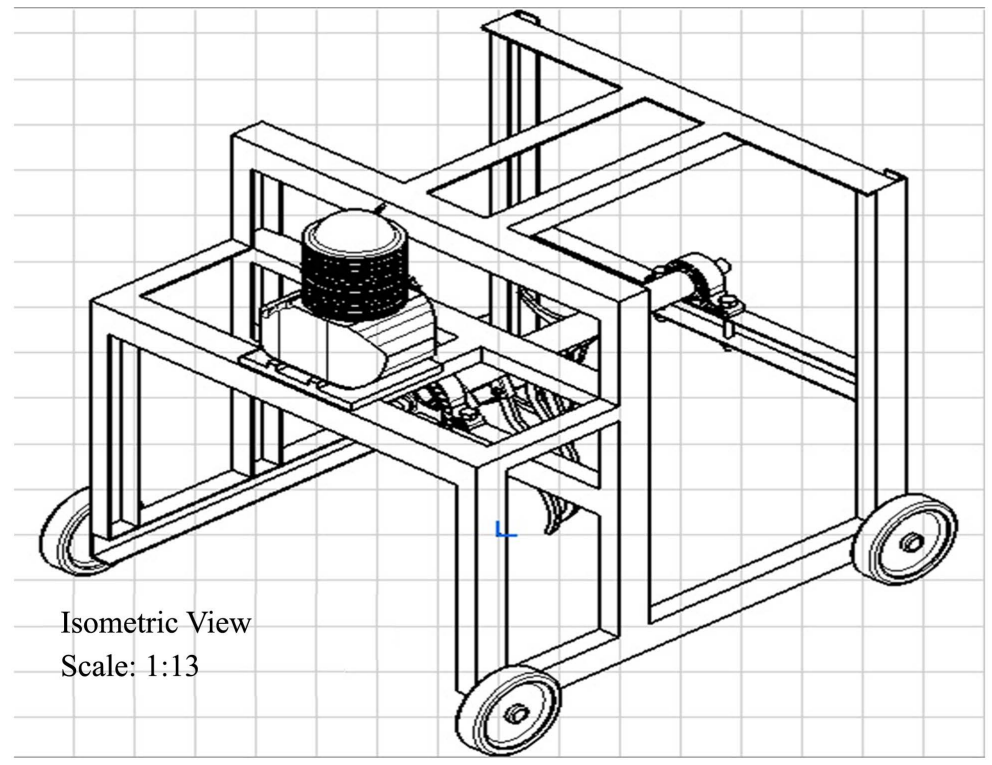

Figure 13. Isometric view of machine.

\section{Working}

The engine is started by kicking; the power which is available at output shaft of engine is transferred to the rotary shaft through chain drive. The required speed of 20 - $25 \mathrm{rpm}$ is gained by the keeping smaller sprocket having teeth of 11 and larger sprocket of teeth 44 . 


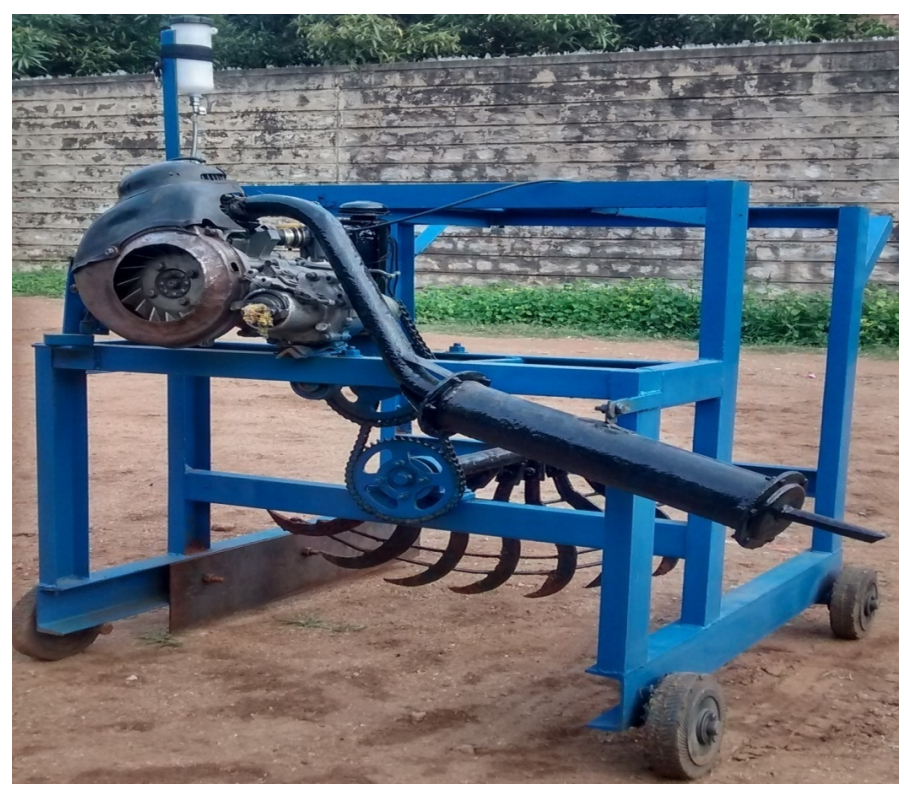

Figure 14. Fully assembled ginger harvesting machine.
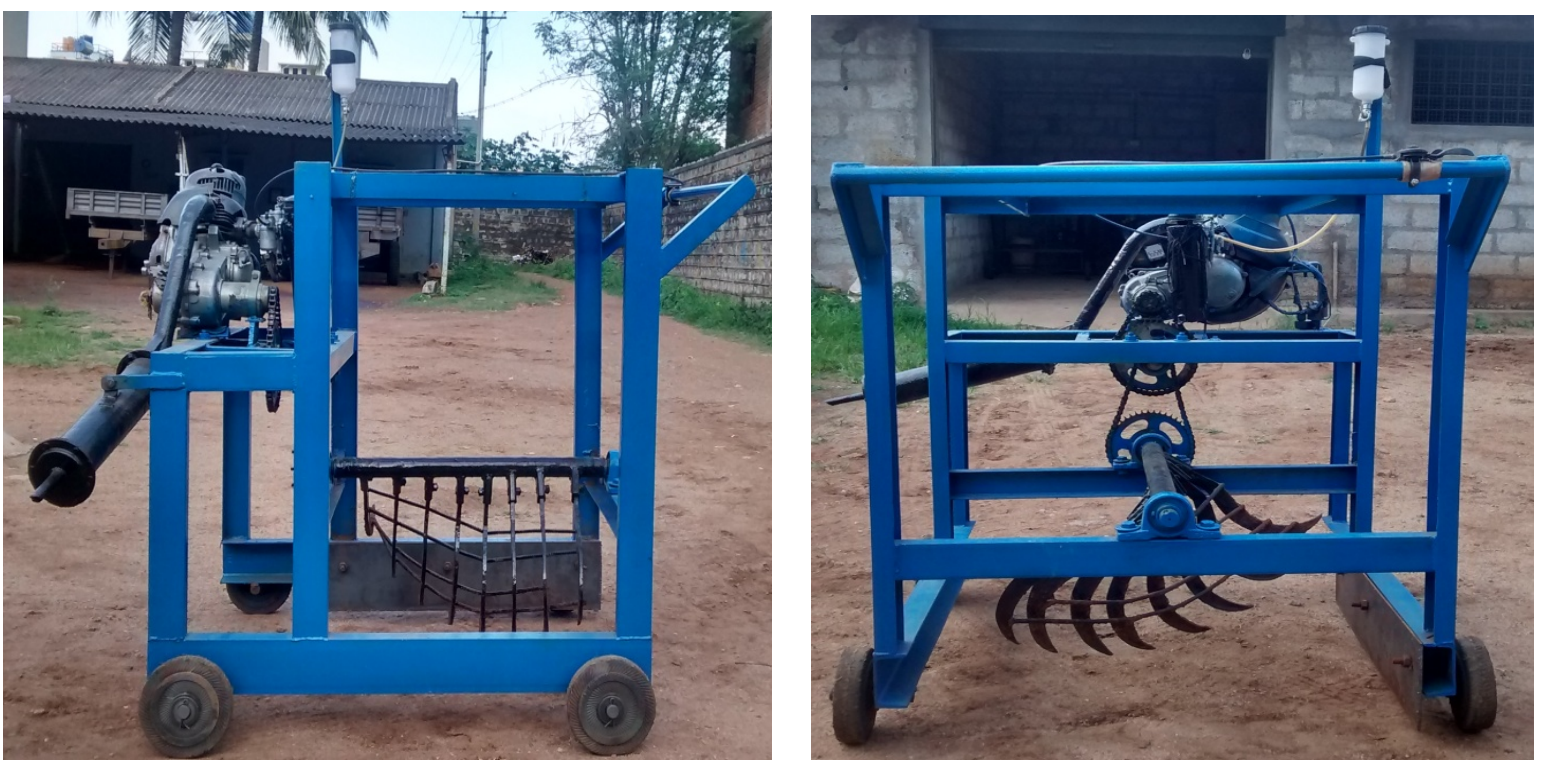

Figure 15. Different views of machine.

In running, the blades hit the bed one after the other not at a time so it is easy to move forward. The screener separates the ginger from soil and provides same by blades without affecting ginger. Then ginger has to be collected manually.

\section{Results and Discussion}

Comparisons are made between manual and machine harvesting shown in Figure 16. At present day ginger is harvested manually with the aid of labours, they demand Rs 100 per $60 \mathrm{~kg}$ of ginger (particularly in Hassan). In an hector ( 1 hector $=2.4710$ acre) of land approximately 4.72 tonnes $(47,200 \mathrm{~kg}$ ) are grown [1], so the total cost for an hector is approximate to Rs. 78,666. But using this machine $60 \mathrm{~kg}$ of ginger can be recovered Rs. 40 which includes the cost of petrol and person who will handle machine. The wage comparison between manual and machine harvesting is as shown in pie Figure 17. 


\section{Number of Hours Required to Harvest One Acre}

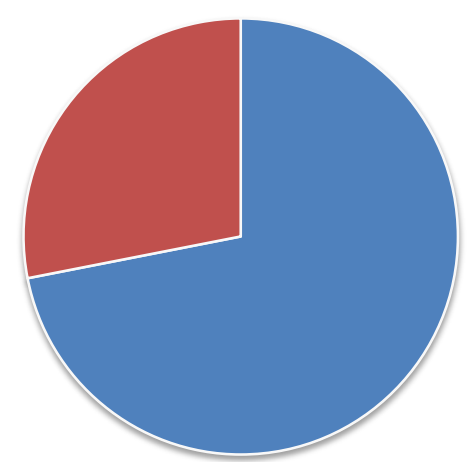

- Manual Harvesting

- Machine Harvesting

Figure 16. Wage comparison.

\section{Wage/Ton/Labour Cost Comparison}

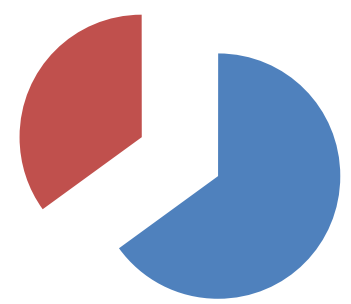

MANUAL HARVESTING

- MACHINE

HARVESTING

Figure 17. Comparison of number of hours required to harvest one acre.

The machine takes minimum time to harvest ginger when compare to manual harvesting. Comparing with manual harvesting $50 \%$ of harvesting time and $60 \%$ of labours are reduced (in manual ginger harvesting 20 - 30 labours are required). The cost of harvesting is reduced by $34 \%$ when compare to manual harvesting.

\section{Conclusion}

The performance of the harvester is evaluated in the field. The cost of the machine is about Rs. 26,000/- and if the farmer buys this machine, he or she can recover the invested money back by harvesting two and half acres (approx.). It is quite simple in design and fabrication, so it can be fabricated at village level. By adapting this machine, problems of the labour crises can be reduced, when compared to manual harvesting with only $18 \%$ of labours being required. It makes the process faster than manual harvesting and hence reduces most of the harvesting time and labours required to operate the machine; thereby, it reduces the labour cost. The machine can be used by a maximum number of farmers; definitely farmer can overcome the labour crisis problem. The productivity can also be increased. This study leaves a wide scope for future investigations. In future it can be automated through tractors with the aid of PTO (Power Take Off) shaft. Collector can be used for collecting the ginger.

\section{References}

[1] Anandaraj, M. (2014) ICAR-Indian Institute of Spices Research, Kozhikode, Kerala.

[2] Rachner, H.G. iwis (wirbewegen die welt) Chain Design and Construction, German.

[3] Bernacki, H., Haman, J. and Kanafojski, C. (1972) Agricultural Machines, Theory and Construction. Vol. 1, Scientific Publications Foreign Cooperation Center, Warsaw, 513.

[4] Hendrick, J.G. and Gill, W.R. (1971) Rotary-Tiller Design Parameters: Part I. Direction of Rotation. Transactions of 
the ASAE, 14, 669-674, 683.

[5] Zareiforoush, H. (2010) Rotary Tiller Design Proportional to a Power Tiller using Specific Work Method (SWM). Department of Mechanical Engineering of Agricultural Machinery, Faculty of Agriculture, University of Urmia, Urmia.

[6] Das, J.B.K. and Shrinivasa Murthy, P.L. (2012) Design of Machine Elements. 7th Revised Edition, Sapna Publications, Bangalore. 